\title{
EVIDENCIAÇÃO AMBIENTAL DAS EMPRESAS DO SEGMENTO DE PAPEL E CELULOSE
}

\section{ENVIRONMENTAL EVIDENCE OF PAPER AND CELLULOSE SEGMENT COMPANIES}

\author{
Lais Leoni Forechi ${ }^{1}$ \\ Orcid: https://orcid.org/0000-0001-8414-0454
}

Diane Rossi Maximiano Reina²

Orcid: https://orcid.org/0000-0001-9683-9991

\section{Donizete Reina ${ }^{3}$}

Orcid: https://orcid.org/0000-0001-6217-2324

\section{Laís Franca Narciso ${ }^{4}$}

Orcid: https://orcid.org/0000-0002-5596-9236

1,2,3,4 (Universidade Federal do Espírito Santo - UFES)

\section{RESUMO}

O objetivo deste estudo foi investigar o nível de evidenciação ambiental e o grau de legibilidade dos relatórios financeiros em empresas do segmento de papel e celulose. O estudo foi realizado por meio da estrutura conceitual proposta por Murcia et al. (2008) com teste de correlação linear de Pearson e com cálculo do grau de complexidade extraído por meio do programa “Gunning's Fog Index". As empresas apresentam média de disclosure verde mais frequente na forma declarativa. A correlação entre as variáveis, o tamanho da empresa, o endividamento, empresa de auditoria foi negativa. Adicionalmente, identificou-se que aproximadamente $87 \%$ das empresas apresentaram baixo grau de legibilidade. A empresa Suzano, apresentou no ano de 2015 um relatório ambiental com grau de complexidade de leitura $46 \%$ acima do que é considerado informação complexa (15 graus) e apresentou no ano de 2016 demonstrações financeiras 47\% acima do que é considerado como informação complexa.

Palavras-chave: Contabilidade Ambiental. Evidenciação Ambiental. Disclosure Verde.

\section{ABSTRACT}

The objective of this study was to investigate the level of environmental disclosure and the readability of financial reports in companies in the paper and pulp segment. The study was carried out through the conceptual framework proposed by Murcia et al. (2008) with Pearson's linear correlation test and the calculation of the degree of complexity extracted through the "Gunning's Fog Index" program. Companies present the most frequent green disclosure average in the declarative form. The correlation between variables, company size, indebtedness, audit firm was negative. Additionally, it was identified that approximately $87 \%$ of companies had a low degree of readability. In the year 2015, Suzano presented an environmental report with a reading complexity of $46 \%$ above what is considered complex information (15 degrees) and presented in the year 2016 financial statements $47 \%$ above what is considered as complex information.

Keywords: Environmental Accounting. Environmental Evidence. Green Disclosure. 


\section{INTRODUÇÃO}

Nos últimos anos a preocupação com o meio ambiente apresenta-se significativa, não só pela necessidade de preservar os recursos naturais como também minimizar os impactos negativos das ações antrópicas no meio ambiente. A sociedade passou a prestar mais atenção na responsabilidade ambiental das empresas, que por sua vez, se preocupam mais com o meio ambiente, para não comprometerem sua imagem, não perderem valor no mercado e não sofrerem penalidades caso cometam alguma infração ambiental (COSTA; MARION, 2007).

Para tanto, a contabilidade ambiental veio como um ramo da contabilidade que pretende contribuir de forma considerável para a produção e disseminação de conhecimentos na vertente ambiental (DOS REIS; NOGUEIRA; TARIFA, 2012). A contabilidade ambiental vem para viabilizar o levantamento de ativos, passivos e custos ambientais das entidades. Sendo que, segundo Rodrigues, Machado e Cruz (2011), os custos são elementos essenciais para uma boa gestão estratégica nas empresas, visando contribuir com melhores resultados e preservação da continuidade do negócio.

Diante disso, por meio da evidenciação contábil ambiental (disclosure ambiental), pode-se verificar quais as empresas que realizam essas contabilizações e em qual nível quantitativo encontram-se essas evidenciações, visto que a legislação contábil atual não obriga a divulgação desses dados. Assim, esta pesquisa se propõe a investigar: Qual o nível de evidenciação ambiental e legibilidade das empresas do ramo de papel e celulose nos anos de 2015 e 2016? Dessa forma, esta pesquisa tem como objetivo investigar o nível de evidenciação ambiental, grau de legibilidade dos relatórios e a associação do nível de evidenciação com as variáveis tamanho, rentabilidade, endividamento, empresas auditadas por Big Four de auditoria em empresas do segmento de papel e celulose listadas na bolsa de valores Brasil, Bolsa e Balcão (B3).

Segundo Altoé et al. (2013), as informações no âmbito ambiental, apesar de classificadas como divulgação voluntária, passaram a ser divulgadas no Brasil juntamente com as informações de cunho social, nas últimas décadas, principalmente a partir dos anos 90. Desse modo, nota-se que a presente pesquisa é importante para o avanço do conhecimento na vertente ambiental, podendo trazer uniformização na análise da evidenciação ambiental, permitindo comparação quanto ao comprometimento das empresas com o meio ambiente e pelo fato de a evidenciação poder influenciar na imagem da entidade e na geração ou economia de suas riquezas. Nesse pensamento, apresenta-se o caso do desastre ambiental em Mariana, em que a empresa envolvida, companhia Samarco, de acordo com Galvão, Monteiro e Lima (2018), divulgou entre os anos de 2008 e 2014 uma média de 16,19\% de sentenças relacionadas ao meio ambiente e após o desastre, apresentou em seu Balanço de Ações de 2015, 25,29\% de sentenças sobre esse tema, o que sugere que a empresa passou a se preocupar mais em regularizar e evidenciar suas ações ambientais para a sociedade.

Os estudos em relação às evidenciações contábeis das empresas na questão ambiental apresentam volume limitado e poucos buscam obter explicações e relações para as possíveis motivações para o "disclosuse verde", visto que esse não é exigido 
em nenhuma legislação atualmente. Percebe-se então uma lacuna a ser preenchida pela presente pesquisa, que contribuirá para maior exploração e diagnóstico do cenário nessa área.

O presente trabalho está estruturado em cinco seções. Esta seção inicial apresenta a introdução e contextualiza o leitor sobre os objetivos e as justificativas do tema escolhido; a segunda seção expõe a fundamentação teórica; na terceira seção, apresenta-se a metodologia, a amostra e os procedimentos para a coleta e análise dos dados; na quarta seção, realiza-se a análise crítica dos resultados obtidos; na quinta seção encontram-se as considerações finais, e por fim, elencam-se as referências utilizadas na pesquisa.

\section{FUNDAMENTAÇÃO TEÓRICA}

\subsection{CONTABILIDADE E EVIDENCIAÇÃO AMBIENTAL}

Conforme Santos et al. (2001), a contabilidade é responsável por gerar informações para auxiliar o gerenciamento das empresas com o objetivo de garantir sua continuidade, sendo a contabilidade ambiental, por sua vez, o estudo do patrimônio ambiental (bens, direitos e obrigações ambientais) das entidades, realizando a identificação, mensuração e evidenciação dos eventos ambientais, com o objetivo de fornecer essas informações aos seus usuários, internos e externos. Diante disso, é possível compreender que a contabilidade ambiental pode também auxiliar o objetivo macro da contabilidade, que é, conforme citado acima, a continuidade da entidade.

Dentre as informações dos eventos ambientais, destacam-se os gastos e ações ambientais decorrentes das atividades operacionais da empresa, que reconhece seus compromissos com o meio ambiente e, a partir daí, visualiza medidas preventivas que possam contribuir para fortalecer ou melhorar sua imagem perante a sociedade e evitar possíveis problemas legais (TINOCO; KRAEMER, 2011).

Os gastos referem-se aos custos e despesas ambientais incorridos na entidade. Ribeiro (2006) definiu despesas ambientais como gastos ambientais decorrentes da área administrativa, como por exemplo, despesas com salários de pessoal da área ambiental, insumos consumidos na pesquisa, seleção e aquisição de itens necessários nessa área, e conceituou custos ambientais como gastos incorridos quando do gerenciamento dos impactos das atividades da empresa que estão diretamente ou indiretamente relacionados à proteção do meio ambiente, como exemplo, tratamento e disposição dos resíduos poluentes dos produtos desenvolvidos pela empresa. Tais conceitos estão de acordo com os defendidos por Antonovz (2014), que ressalva que a classificação de custos e despesas na contabilidade ambiental é a mesma aplicada à contabilidade tradicional. Os gastos ambientais podem, inclusive, modificar a estrutura de capital da empresa, alterando a participação de capitais de terceiros em relação à participação dos acionistas (PEREIRA; LERNER; VENDRUSCOLO, 2018).

Existem ainda os ativos e passivos ambientais. Os ativos ambientais são apresentados por Ribeiro (2006) como os bens e direitos da entidade capazes de gerar benefício econômico futuro visando à preservação, proteção e recuperação ambiental, como um equipamento que reduz a emissão de poluentes durante o processo produtivo. Já os 
passivos ambientais têm sua definição colocada por Teixeira, Nossa e Donatti (2007) como todos os compromissos da empresa que irão resultar num provável consumo de recurso visando atender a obrigações advindas de questões ambientais, como por exemplo, provisões de gastos com recuperações de áreas degradadas.

As receitas ambientais também podem ocorrer numa entidade sendo originadas por vários fatores, como alguns dos citados por Tinoco e Kraemer (2011): receita proveniente de gases e calor, redução no consumo de água, energia e consumo de matérias-primas, entre outros, sendo que esses autores ressaltam que também deve ser considerada receita ambiental o ganho de mercado que a empresa passa a auferir quando a sociedade reconhece sua política de preservação ambiental, dando preferência a seus produtos devido a esse fato.

A evidenciação contábil de forma geral pode ser divulgada nas Demonstrações Contábeis, nas Notas Explicativas, nos Relatórios de Auditores e da Administração ou em demonstrativos suplementares, sempre com o objetivo de fornecer informações completas a todos os usuários, atendendo às suas necessidades (IUDÍCIBUS, 2004).

Com relação à evidenciação das informações ambientais, Tinoco e Kraemer (2011) registram que as empresas evidenciam essas informações por meio do Balanço Social, que inclui o Balanço Ambiental, ou também por meio do Relatório da Administração, e da divulgação dos Relatórios Ambientais ou Socioambientais, sendo que algumas empresas brasileiras realizam a evidenciação ambiental também no exterior. Conforme relatado por Rover et al. (2012) as normas contábeis no
Brasil não obrigam a divulgação de informações ambientais das empresas, porém regulamentam tais publicações, determinando como realizá-las, caso a entidade decida pela divulgação.

As normatizações atuais são as seguintes: Parecer de Orientação n.15/87 da Comissão de Valores Mobiliários, que indica que as evidenciações ambientais estejam no Relatório da Administração; na Norma e Procedimento de Auditoria $N^{\circ} 11$ do Instituto dos Auditores Independentes do Brasil - IBRACON que estabelece que os ativos e passivos ambientais devam ser registrados nos demonstrativos contábeis; e na Resolução $N^{\circ}$ 1.003/04 do Conselho Federal de Contabilidade que aprovou a Norma Brasileira de Contabilidade Técnica No 15 - NBC T 15 que cita todos os itens que devem ser evidenciados, como por exemplo, investimentos e gastos com manutenção nos processos operacionais para a melhoria do meio ambiente, quantidade de processos ambientais, administrativos e judiciais movidos contra a entidade; e outros.

A IBRACON por intermédio da NPA n 11, já citada acima, ressalta ainda que existe um retorno do investimento ambiental e de sua publicação para a empresa, sendo uma forma de contribuição com a qualidade de vida humana e um investimento industrial, diante do grande público, imprensa e dos órgãos.

Antonovz (2014) constatou que uma grande preocupação da contabilidade atualmente é oferecer aos usuários um bom nível de informações sobre a entidade, inclusive informações ambientais, que se mostram cada vez menos acessória e mais decisiva para a sociedade e para as organizações. Para Altoé et al. (2013) a divulgação das 
informações ambientais empresariais torna-se cada vez mais presente por ocasião da publicação dos relatórios contábeis obrigatórios, de modo que os investidores e a sociedade civil em geral têm cada vez mais interesses nas práticas de gestão ambiental a fim de mitigar os danos causados pelas atividades das empresas.

Vale lembrar a respeito da legitimidade organizacional que é continuamente construída e mantida por meio de ações simbólicas, as quais estruturam parte da imagem pública de uma organização. Entre essas ações simbólicas, tem-se a evidenciação ambiental que se apresenta como um efetivo método para conduzir as impressões do público externo e auxiliar a garantia da continuidade dos negócios nos dias atuais (SILVA et al., 2013). Os autores Rodrigues, Machado e Da Cruz (2011) reafirmam esse pensamento relatando a necessidade da evidenciação de todos os gastos e as provisões efetuadas na área ambiental, assim como demais situações relacionadas com a natureza, pois eles podem vir a prejudicar os interesses dos acionistas ou representar riscos para a continuidade da empresa e da sociedade.

\subsection{ESTUDOS SIMILARES}

Altoé et al. (2013) verificaram o nível de divulgações das informações ambientais nas companhias brasileiras do setor siderúrgico e metalúrgico nos anos de 2008 a 2011, obtendo o número de 13 companhias e divulgação de 282 sentenças no total desses setores. Os autores concluíram que está cada vez mais frequente a evidenciação de informações ambientais nas organizações, principalmente nas atividades que causam maiores danos ao meio ambiente.

Com o objetivo de pesquisar sobre as divulgações realizadas pelas companhias envolvidas no desastre ambiental ocorrido em Mariana (MG), em novembro de 2015, e seus efeitos patrimoniais e no resultado do período, Toledo Junior e Ribeiro (2017) identificaram que a Mineradora Samarco apresentou em suas divulgações contábilfinanceiras relatos com o intuito de elucidar sobre o planejamento e ações executados pela empresa a fim de atenuar os impactos do rompimento da barragem, visando alcançar e atender diversos stakeholders que passaram a se interessar mais por suas demonstrações, como agentes econômicos e moradores locais, além dos órgãos governamentais. Já as divulgações das empresas controladoras, Vale S.A. e BHP Billinton, não atendem à teoria dos stakeholders, visto que restringem informações de responsabilidades do ocorrido, não realizando devida prestação de contas a todos os interessados, tal fato inclusive ocasionou abertura de ação por investidores estrangeiros devido à falta de informações sobre o caso e riscos envolvidos.

Tinoco e Robles (2006) também realizaram um estudo exploratório de levantamento das informações ambientais, buscando identificar a preocupação das empresas com a sustentabilidade econômica e o desenvolvimento social, focando em quatro empresas nacionais com atuação global. Após estudos caso a caso das empresas, foi observado pelos autores que as empresas estudadas, que têm suas ações negociadas em bolsas no exterior, apresentam mais detalhes da evidenciação ambiental em seus demonstrativos, Ihes proporcionando um nível de credibilidade e de responsabilidade mais significativo. 
Já Rover et al. (2012) selecionou 57 empresas enquadradas como alto impacto ambiental, sendo elas dos setores de extração e tratamento de minerais; metalúrgico; químico; papel e celulose; indústria de couros e peles; transporte, terminais, depósitos e comércio (de combustíveis, derivados de petróleo e produtos químicos) e pesquisou suas Demonstrações Financeiras Padronizadas e seus Relatórios de Sustentabilidade (RS) do período de 2005 a 2007, investigando os fatores que determinam a divulgação voluntária ambiental. Dos sete fatores investigados: tamanho, rentabilidade, endividamento, empresa de auditoria, sustentabilidade, internacionalização e publicação do RS, as variáveis tamanho da empresa, empresa de auditoria, sustentabilidade e publicação do RS foram as mais relevantes para a explicação do disclosure voluntário de informações ambientais.

Outra pesquisa que explorou o tema das possíveis explicações para a divulgação voluntária foi elaborada por Murcia et al. (2008), que identificou as seguintes relações: a boa notícia é apresentada de forma declarativa no Relatório da Administração; a notícia neutra tende a estar nas notas explicativas com tipo de evidencia quantitativa monetária; e as variáveis que apresentaram significância com explicação da evidenciação ambiental foram tamanho da empresa, empresa de auditoria e participação no ISE.

Marquezan et al. (2015) realizaram um estudo a partir da pesquisa de Murcia et al. (2008), aprofundando a estatística descritiva e análise de correlação para confirmar a relação de 8 variáveis (tamanho, rentabilidade, endividamento, auditoria, participação no ISE, ações no mercado norteamericano, Governança Corporativa e nível médio de potencial impacto ambiental) com fatores que levam as organizações a divulgar informações ambientais. A conclusão obtida foi que a participação no ISE, a rentabilidade e o nível de potencial de impacto apresentam relação positiva com o nível de disclosure verde, já o tamanho da empresa e nível de governança corporativa não foram fatores significativos para explicação desses.

Dos Reis, Nogueira e Tarifa (2012) realizaram um levantamento da quantidade de livros publicados existentes sobre o tema "Contabilidade Ambiental", em língua portuguesa, nos anos de 2000 a 2010. Constatou-se que o número de publicações é insuficiente para atender ao tema e que os motivos para isso podem ser diversos, como falta de interesse editorial e o desconhecimento dos profissionais contábeis a respeito da amplitude e da importância da Contabilidade Ambiental para as empresas.

\section{PROCEDIMENTOS METODOLÓGICOS}

A pesquisa tem caráter descritivo por analisar o nível de evidenciação ambiental das empresas do ramo de papel e celulose nos anos de 2015 e 2016 e a sua correlação com as variáveis tamanho, rentabilidade, endividamento, empresas de auditoria, e o índice de sustentabilidade empresarial. De acordo com Gil (2008), as pesquisas descritivas contemplam aquelas que objetivam estudar as características de um determinado grupo, população ou fenômeno. Além disso, esse estudo é documental, pois a fonte de dados são os relatórios disponíveis no site da B3 e das respectivas empresas nos anos de 2015 e 2016, 
sendo eles as Demonstrações Financeiras e o Relatório de Sustentabilidade ou Similar (LAKATOS; MARCONI, 2003). De acordo com Ludke e André (1986) a análise documental constitui uma técnica importante na pesquisa qualitativa, seja complementando informações obtidas por outras técnicas, seja desvelando aspectos novos de um tema ou problema.

A população do estudo é composta pelas empresas do ramo de Papel e Celulose listadas na B3 nos anos de 2015 e 2016. Esse ramo foi escolhido por ser de potencial poluidor de alto impacto, segundo a legislação ambiental (Lei n 6.938/1981) e suas alterações posteriores, especialmente pela Lei $n^{\circ} 10.165 / 2000$, e por ser um ramo que apresenta grande interação com o meio ambiente ao desenvolver suas atividades operacionais, visto que produz florestas. Optou-se por realizar o estudo em um ramo de atividade com relatórios disponíveis para leitura e busca de informações com termos específicos com a possibilidade de analisar um horizonte temporal maior.

O recorte inicial do estudo contemplou seis empresas do ramo de papel e celulose (Fibria Celulose S.A., Celulose Irani S.A., Klabin S.A., Santher Fábrica de Papel Santa Therezinha S.A., Suzano Holding e Suzano Papel e Celulose S.A.), porém ao analisar cada uma delas foi observado que a empresa Santher possui atividades diferentes das demais, não possuindo florestas/celulose em seus negócios, se diferenciando significativamente das atividades operacionais das demais empresas, e as empresas Suzano Hold e Suzano Papel compõem o mesmo grupo empresarial, possuindo as mesmas Demonstrações Contábeis. Diante dos fatos descritos, a amostra passou a ser composta por quatro empresas: Fibria, Irani, Klabin e Suzano.

Os documentos escolhidos foram as Demonstrações Financeiras Padronizadas e os Relatórios de Sustentabilidade ou Similar das organizações, considerando que, de acordo com Mussoi e Bellen (2010), os relatórios socioambientais são os documentos que divulgam informações ambientais com melhor desempenho, tanto quantitativamente quanto qualitativamente. E segundo Murcia et al. (2008), relevância e comparabilidade são duas premissas fundamentais para realização de um estudo, as quais foram atendidas com os documentos utilizados, visto que todas elas possuem e divulgam tais documentos.

Os dados para mensuração do nível de evidenciação ambiental foram coletados a partir da leitura dos relatórios para a identificação de informações sobre os itens apresentados no Quadro 1, o qual apresenta 8 categorias e 36 subcategorias. Para utilização dessa métrica a mensuração foi realizada preenchendo cada subcategoria dessa estrutura conceitual, utilizando " 0 ", caso a empresa não apresentasse informação para aquele item, e "1" caso apresentasse. A partir daí, podese obter um percentual de evidenciação ambiental para cada organização e ano pesquisado. 
Quadro 1 - Estrutura conceitual para medir o nível de evidenciação ambiental

\begin{tabular}{|c|c|c|}
\hline Categorias & & Subcategorias \\
\hline \multirow{5}{*}{ 1. Políticas Ambientais } & 01 & Declaração das políticas/práticas/ações atuais e futuras \\
\hline & 02 & Estabelecimento de metas e objetivos ambientais \\
\hline & 03 & $\begin{array}{l}\text { Declaração indicando que a empresa está em obediência (compliance) com as } \\
\text { leis, licenças, normas e órgãos ambientais }\end{array}$ \\
\hline & 04 & Parcerias ambientais \\
\hline & 05 & Prêmios e participações em índices ambientais \\
\hline \multirow{3}{*}{$\begin{array}{l}\text { 2. Sistemas de } \\
\text { Gerenciamento Ambiental }\end{array}$} & 06 & ISOs 9.001 e/ou 14.001 \\
\hline & 07 & Auditoria ambiental \\
\hline & 08 & Gestão ambiental \\
\hline \multirow{8}{*}{$\begin{array}{l}\text { 3. Impactos dos produtos } \\
\text { e Processos no Meio } \\
\text { Ambiente }\end{array}$} & 09 & Desperdícios/ Resíduos \\
\hline & 10 & Processo de acondicionamento (Embalagem) \\
\hline & 11 & Reciclagem / Reaproveitamento \\
\hline & 12 & Desenvolvimento de produtos ecológicos \\
\hline & 13 & Impacto na área de terra utilizada \\
\hline & 14 & Uso eficiente/ Reutilização de água \\
\hline & 15 & Vazamentos e derramamentos \\
\hline & 16 & Reparos aos danos ambientais \\
\hline \multirow{4}{*}{ 4. Energia } & 17 & Conservação e/ou utilização mais eficiente nas operações \\
\hline & 18 & Utilização de materiais desperdiçados na produção de energia \\
\hline & 19 & Discussão sobre a preocupação com a possível falta de energia \\
\hline & 20 & Desenvolvimento/ exploração de novas fontes de energia \\
\hline \multirow{6}{*}{$\begin{array}{l}\text { 5. Informações Financeiras } \\
\text { Ambientais }\end{array}$} & 21 & Investimentos ambientais \\
\hline & 22 & Custos / despesas ambientais \\
\hline & 23 & Passivos/Provisões ambientais \\
\hline & 24 & Práticas contábeis de itens ambientais \\
\hline & 25 & Seguro ambiental \\
\hline & 26 & Ativos ambientais tangíveis e intangíveis \\
\hline \multirow{2}{*}{$\begin{array}{l}\text { 6. Educação, Treinamento } \\
\text { e Pesquisas }\end{array}$} & 27 & Educação Ambiental (internamente e/ou comunidade) \\
\hline & 28 & Pesquisas relacionadas ao meio ambiente \\
\hline \multirow{4}{*}{$\begin{array}{l}\text { 7. Mercado de Créditos } \\
\text { de Carbono }\end{array}$} & 29 & Projetos de Mecanismos de Desenvolvimento Limpo (MDL) \\
\hline & 30 & Créditos de carbono \\
\hline & 31 & Emissão de Gases do Efeito Estufa (GEE) \\
\hline & 32 & Certificados de Emissões Reduzidas (CER) \\
\hline \multirow{4}{*}{$\begin{array}{l}\text { 8. Outras Informações } \\
\text { Ambientais }\end{array}$} & 33 & Qualquer menção sobre sustentabilidade/desenvolvimento Sustentável \\
\hline & 34 & Gerenciamento de florestas/ Reflorestamento \\
\hline & 35 & Conservação da biodiversidade \\
\hline & 36 & Stakeholders \\
\hline
\end{tabular}

Fonte: Adaptado de Murcia et al. (2008). 
O Quadro 1 foi atualizado em relação à subcategoria 6 (ISOs 9.001 e/ou 14.001), pois apresentava ISOs 9.000 e 14.000, as quais foram substituídas pelas certificações vigentes atualmente.

Vale ressaltar que além das palavras específicas do quadro, também foi analisado o sentido mais aprofundado de cada uma das subcategorias, procurando não somente uma ou duas palavras, mas também explorando o significado de cada item e o contexto em que ele se encontra, dessa forma pôde-se ainda evitar que palavras que não remetessem a meio ambiente fossem consideradas. Assim, na subcategoria 11 foi adicionada a palavra Reaproveitamento, que apresenta conceito similar à reciclagem e foi identificada em alguns documentos utilizados para coleta de dados. Além disso, o mesmo procedimento foi adotado para a subcategoria de número 12 (Desenvolvimento de produtos ecológicos) para a qual também foram pesquisadas as palavras "bionegócio" e "bioprodutos" e para a subcategoria de número 16 (Reparos aos danos ambientais) para a qual foram pesquisadas as seguintes palavras "restaura" e "compensa".

O presente estudo também busca observar as características das palavras/expressões encontradas para cada subcategoria de acordo com seu tipo de evidência ambiental, conforme sugerido e utilizado por Salomone; Galuccio (2001), Nossa (2002) e Murcia et al. (2008): Declarativa: quando a informação é apresentada somente de forma descritiva; Quantitativa não monetária: quando a informação é evidenciada de forma quantitativa e não financeira, por exemplo: quantidade de hectares de conservação de matas nativas; e Quantitativa monetária: quando a evidenciação é realizada de forma financeira, além de quantitativa, por exemplo: montante de valor utilizado em investimentos ambientais.

Para investigar a correlação entre o nível de evidenciação ambiental com as variáveis tamanho, rentabilidade, endividamento, empresas de auditoria e o índice de sustentabilidade empresarial, utilizou-se a correlação linear de Spearman.

\subsection{VARIÁVEIS INVESTIGADAS}

Inicialmente foram identificadas e selecionadas variáveis explicativas para evidenciação ambiental a partir de estudos realizados, as quais foram consideradas como variáveis para análise de correlação:

a) Tamanho (TAM): Mazzioni et al. (2017) e Murcia et al. (2008) alegam que grandes empresas podem atrair maior atenção dos investidores e governo, assim espera-se delas padrões mais elevados na divulgação das informações ambientais. Fernandes (2013) constatou associação positiva entre tamanho da empresa com evidenciação ambiental. Para a variável tamanho utilizou-se o logaritmo natural do ativo total da empresa.

b) Rentabilidade (RENT): enquanto alguns estudos revelam que a rentabilidade não possui associação positiva com o nível de evidenciação ambiental (MURCIA et al., 2008; ALMEIDA-SANTOS et al., 2012; ROVER et al., 2012), estudos mais recentes afirmam relação positiva entre evidenciação ambiental e rentabilidade (MARQUEZAN et al., 2015; MAZZIONI et al., 2017). Murcia et al. (2008) 
relata que esperava obter relação positiva entre o diclosure e a rentabilidade a partir da relação de que empresas com maior rentabilidade divulgam mais informações para se diferenciarem de seus concorrentes, porém essa relação não foi comprovada. Para análise dessa variável foi utilizado o índice Retorno sobre o Ativo (ROA), em pontos percentuais, assim como Murcia et al. (2008) e Rover et al. (2012).

c)Endividamento (END): para calculá-lo foi utilizado o Índice de Endividamento Geral (PC+PNC) / AT. Espera-se que organizações com maior nível de endividamento ofereçam mais informações para seus credores, a fim de obter maior confiança deles (ROVER et al., 2012). Marquezan et al. (2015) comprovaram essa relação no que diz respeito a diclosure verde.

d) Auditoria (AUD): essa variável foi estudada como dicotômica ou binária, de modo que caso a organização seja auditada por uma do grupo das Big Four (Pricewaterhouse Coopers, Deloitte Touche Tohmatsu, KPMG e Ernst \& Young) ela terá valor igual a 1 e caso não seja auditada por uma delas, terá valor igual a 0 (MURCIA et al., 2008; ROVER et al.,
2012; MARQUEZAN et al., 2015). Murcia et al. (2008) e Rover et al. (2012) identificaram relação positiva entre este item e evidenciação ambiental, podendo ser explicada pelo fato de que empresas de auditoria podem influenciar numa maior accountability no quesito evidenciação ambiental.

e) ParticipaçãonoISE(ÍndicedeSustentabilidade Empresarial): essa variável foi tratada da mesma forma que a variável acima, dicotômica/ binária, se a empresa participar do índice, terá valor igual a 1 e se não participar terá valor igual a 0 . Constatou-se que organizações que participam do ISE apresentam maior disclosure verde, logo associação positiva entre eles (MURCIA et al., 2008; ALMEIDA-SANTOS et al., 2012; MARQUEZAN et al., 2015; ROVER et al., 2012).

\section{RESULTADOS E DISCUSSÕES}

Este tópico contém a descrição e análise dos dados coletados, relacionando primeiramente um resumo das informações coletadas sobre o nível de evidenciação ambiental por empresa de acordo com a Tabela 1.

Tabela 1 - Resumo do nível de evidenciação ambiental por empresa

\begin{tabular}{l|c|c|c|c|c|c}
\hline & \multicolumn{2}{|c|}{2015} & \multicolumn{2}{c|}{2016} & \multicolumn{2}{c}{ Média (por empresa) } \\
\hline Subcategorias & $\mathrm{N}=36$ & $\%$ & $\mathrm{~N}=36$ & $\%$ & $\mathrm{~N}=36$ & $\%$ \\
\hline Empresas & & & & & & \\
\hline Fibria & 27 & $75 \%$ & 26 & $72 \%$ & 26,5 & $74 \%$ \\
\hline Irani & 25 & $69 \%$ & 27 & $75 \%$ & 26 & $72 \%$ \\
\hline Kablin & 20 & $56 \%$ & 22 & $61 \%$ & 21 & $58 \%$ \\
\hline Suzano & 24 & $67 \%$ & 23 & $64 \%$ & 23,5 & $65 \%$ \\
\hline Média (Ramo de atividade) & 24 & $67 \%$ & 24,5 & $68 \%$ & 24,25 & $67 \%$ \\
\hline
\end{tabular}

Fonte: Dados da pesquisa. 
Diante dos dados expostos na Tabela 1, percebese que o nível de evidenciação ambiental do ramo de papel e celulose foi de $67 \%$ no ano de 2015 e de $68 \%$ no ano de 2016. Apesar do aumento discreto, haveria campo para futuras pesquisas analisarem um horizonte temporal maior com vistas a verificar se esse aumento na evidenciação ambiental tende a aumentar e quais variáveis poderiam estar relacionadas a esse aumento na evidenciação.

O nível de diclosure verde exposto acima não corrobora com um estudo similar realizado por Almeida et al. (2012) que analisou o nível de evidenciação ambiental por meio do mesmo método para uma amostra de 100 empresas que compunham o ranking da Revista Exame como as maiores empresas brasileiras de capital aberto, tendo como proxy o valor de mercado de
2009. Tais empresas evidenciaram uma média de $27,78 \%$ do total de informações ambientais a serem divulgadas, ou seja, média bem abaixo da encontrada pela presente pesquisa, sugerindo que tal ramo se encontra num nível elevado quando comparada aos demais ramos de atividades. Além disso, observando cada empresa, é possível afirmar que, realizando a média para os dois anos, a empresa Fibria apresenta maior nível de evidenciação, seguida pela empresa Irani, após pela Suzano e por fim, pela empresa Klabin.

Outra análise realizada é a respeito do nível de evidenciação de cada categoria em cada ano e para cada organização estudada, como pode ser observada na Tabela 2.

Tabela 2 - Nível de evidenciação por empresa e por categoria

\begin{tabular}{|c|c|c|c|c|c|c|c|c|c|c|c|c|c|c|c|c|}
\hline \multirow{3}{*}{ Categorias } & \multicolumn{4}{|c|}{ FIBRIA } & \multicolumn{4}{|c|}{ IRANI } & \multicolumn{4}{|c|}{ KABLIN } & \multicolumn{4}{|c|}{ SUZANO } \\
\hline & \multicolumn{2}{|c|}{2015} & \multicolumn{2}{|c|}{2016} & \multicolumn{2}{|c|}{2015} & \multicolumn{2}{|c|}{2016} & \multicolumn{2}{|c|}{2015} & \multicolumn{2}{|c|}{2016} & \multicolumn{2}{|c|}{2015} & \multicolumn{2}{|c|}{2016} \\
\hline & 5 & $100 \%$ & 5 & $100 \%$ & 4 & $80 \%$ & 5 & $100 \%$ & 4 & $80 \%$ & 5 & $100 \%$ & 5 & $100 \%$ & 5 & $100 \%$ \\
\hline $\begin{array}{l}\text { 2. Sistemas de } \\
\text { Gerenciamento Ambiental }\end{array}$ & 2 & $67 \%$ & 2 & $67 \%$ & 3 & $100 \%$ & 3 & $100 \%$ & 2 & $67 \%$ & 2 & $67 \%$ & 2 & $67 \%$ & 1 & $33 \%$ \\
\hline $\begin{array}{l}\text { 3. Impactos dos produtos } \\
\text { e Processos no Meio } \\
\text { Ambiente }\end{array}$ & 6 & $75 \%$ & 5 & $63 \%$ & 7 & $88 \%$ & 6 & $75 \%$ & 4 & $50 \%$ & 4 & $50 \%$ & 5 & $63 \%$ & 6 & $75 \%$ \\
\hline 4. Energia & 4 & $100 \%$ & 4 & $100 \%$ & 1 & $25 \%$ & 3 & $75 \%$ & 3 & $75 \%$ & 3 & $75 \%$ & 2 & $50 \%$ & 2 & $50 \%$ \\
\hline $\begin{array}{l}\text { 5. Informações Financeiras } \\
\text { Ambientais }\end{array}$ & 3 & $50 \%$ & 3 & $50 \%$ & 1 & $17 \%$ & 2 & $33 \%$ & 1 & $17 \%$ & 1 & $17 \%$ & 3 & $50 \%$ & 2 & $33 \%$ \\
\hline $\begin{array}{l}\text { 6. Educação, Treinamento e } \\
\text { Pesquisas }\end{array}$ & 2 & $100 \%$ & 2 & $100 \%$ & 2 & $100 \%$ & 2 & $100 \%$ & 2 & $100 \%$ & 2 & $100 \%$ & 2 & $100 \%$ & 2 & $100 \%$ \\
\hline $\begin{array}{l}\text { 7. Mercado de Créditos de } \\
\text { Carbono }\end{array}$ & 1 & $25 \%$ & 1 & $25 \%$ & 3 & $75 \%$ & 2 & $50 \%$ & 1 & $25 \%$ & 1 & $25 \%$ & 1 & $25 \%$ & 1 & $25 \%$ \\
\hline $\begin{array}{l}\text { 8. Outras Informações } \\
\text { Ambientais }\end{array}$ & 4 & $100 \%$ & 4 & $100 \%$ & 4 & $100 \%$ & 4 & $100 \%$ & 3 & $75 \%$ & 4 & $100 \%$ & 4 & $100 \%$ & 4 & $100 \%$ \\
\hline
\end{tabular}

Fonte: Dados da pesquisa.

Ainda conforme a Tabela 2 verifica-se que o item 'Educação, Treinamento e Pesquisas' apresentou nível de evidenciação de 100\% em suas subcategorias, em todas as organizações nos dois anos estudados, mostrando assim grande preocupação das empresas com a comunidade do entorno, seus colaboradores e pesquisas ambientais. Sendo que no ano de 2016, além 
dessa categoria ter atingido $100 \%$, as 'Políticas Ambientais' e 'Outras Informações Ambientais' também atingiram esse nível de disclosure verde em todas as organizações. Tais dados aproximamse dos encontrados por Murcia et al. (2008) que identificaram como categoria predominante de evidenciação a de 'Políticas ambientais', que também teve alto índice nesta pesquisa.

Outra categoria que demonstra um fato interessante é a 'Mercado de Créditos de Carbono' que apresentou pelo menos uma evidenciação em todos os anos por cada uma das empresas estudadas. Essa perspectiva não foi constatada por Altoé et al. (2013), pois os mesmos autores não identificaram, praticamente nenhuma sentença relacionada a esta categoria nos setores de Metalurgia e Siderurgia nos anos de 2008 a 2011.

Com relação ao tipo de evidência, apresentase a Tabela 3, que mostra que a maioria das informações ambientais foi evidenciada de forma declarativa, no entanto não com tanta distância do segundo tipo de evidenciação mais presente que é a quantitativa não monetária. Os dados encontrados não condizem com os estudos realizados por Murcia et al. (2008) que verificaram que as empresas listadas na BM\&FBovespa, em 2006, apresentam em sua maioria, cerca de $67 \%$ das informações do tipo declarativa, 13\% do tipo quantitativa monetária e aproximadamente 20\% do tipo quantitativa não monetária. O mesmo pode ser comparado ao estudo de Altoé et al. (2013), que identificaram em seu estudo um percentual de $69 \%$ das informações evidenciadas com o tipo declarativa, 24\% do tipo quantitativa monetária, 4\% do tipo quantitativa não monetária e 3\% do tipo quantitativa monetária e não monetária. Esses resultados podem indicar evolução no tipo de evidenciação ambiental ao decorrer dos anos e/ou a diferenciação de evidenciação de acordo com o ramo de atividade.

Tabela 3 - Tipo de evidência por ano para o Segmento de Papel e Celulose.

\begin{tabular}{|c|c|c|c|c|c|c|c|}
\hline \multirow{2}{*}{$\begin{array}{l}\text { Segmento Papel e Celulose } \\
\text { Subcategorias }\end{array}$} & \multirow[b]{2}{*}{$N=$} & \multicolumn{2}{|c|}{2015} & \multicolumn{2}{|c|}{2016} & \multicolumn{2}{|c|}{ Total } \\
\hline & & 96 & $\%$ & 98 & $\%$ & 194 & $\%$ \\
\hline \multicolumn{8}{|l|}{ Tipo de Evidência } \\
\hline Declarativa & & 40 & $42 \%$ & 40 & $42 \%$ & 80 & $41 \%$ \\
\hline Quantitativa Não monetária & & 33 & $34 \%$ & 32 & $33 \%$ & 65 & $34 \%$ \\
\hline Quantitativa Monetária & & 23 & $24 \%$ & 26 & $27 \%$ & 49 & $25 \%$ \\
\hline
\end{tabular}

Fonte: Dados da pesquisa.

De acordo com a Tabela 3 pode-se notar também um moderado aumento na quantidade de informações evidenciadas de forma monetária, o que denota aumento na preocupação das empresas em expor informações ambientais financeiras de um ano para o outro.

Relacionando as categorias com o tipo de evidência, Altoé et al. (2013), em sua pesquisa feita para o ramo de Metalurgia e Siderurgia, para os anos de 2008 a 2011, constataram que as categorias 'Políticas Ambientais', 'Sistemas de Gerenciamento Ambiental' e 'Educação, Pesquisa e Treinamento', em alguns desses anos, apresentaram em sua totalidade evidências na forma declarativa, diferenciando-se do ramo de Papel e celulose que mostrou nos anos estudados, pelo menos duas 
subcategorias com informações Quantitativas Não monetárias ou Monetárias, como por exemplo, a subcategoria 'Estabelecimento de metas e objetivos ambientais' que para todos os anos e para todas as empresas apresentou informação Quantitativa Não monetária ou Monetária.
Para investigar a correlação entre o nível de evidenciação ambiental com as variáveis tamanho, rentabilidade, endividamento, empresas de auditoria e o índice de sustentabilidade empresarial apresenta-se, na Tabela 4, a matriz de correlação.

Tabela 4 - Correlação entre as variáveis.

\begin{tabular}{l|l|l|l|l|l|l|l}
\hline \multicolumn{2}{c}{} & EV & TAM & RENT & END & AUD & ISE \\
\hline \multirow{2}{*}{ EV } & Coeficiente & 1 & & & & & \\
\cline { 2 - 8 } & p-valor & & & & & & \\
\hline \multirow{2}{*}{ TAM } & Coeficiente & 0.13 & 1 & & & & \\
\cline { 2 - 9 } & p-valor & 0.76 & & & & & \\
\hline \multirow{2}{*}{ ENDT } & Coeficiente & 0.00 & 0.57 & 1 & & & \\
\cline { 2 - 9 } & p-valor & 1 & 0.14 & & & & \\
\hline \multirow{2}{*}{ AUD } & Coeficiente & -0.60 & -0.81 & -0.40 & 1 & & \\
\cline { 2 - 9 } & p-valor & 0.12 & 0.15 & 0.32 & & & \\
\cline { 2 - 9 } & Coeficiente & -0.57 & $-0.76^{*}$ & -0.25 & $0.76^{*}$ & 1 & \\
\hline \multirow{2}{*}{ ISE } & Coeficiente & -0.16 & 0.55 & 0.22 & -0.11 & -0.58 & 1 \\
\cline { 2 - 9 } & p-valor & 0.70 & 0.16 & 0.60 & 0.80 & 0.13 & \\
\hline
\end{tabular}

Fonte: Dados da pesquisa.

Obs: * significância no nível 0,05.

Ao analisar as informações apresentadas na Tabela 4, observa-se que Endividamento apresentou correlação positiva e estatisticamente significativa ao nível de $5 \%$ com a variável Auditoria. A variável Rentabilidade não apresentou correlação com a variável evidenciação, este resultado diverge dos encontrados por Murcia et al. (2008) que esperavam obter relação positiva entre o diclosure e a rentabilidade a partir da relação de que empresas com maior rentabilidade divulgam mais informações para se diferenciarem de seus concorrentes, porém essa relação não foi comprovada. Também diverge dos estudos de Marquezan et al. (2015) e Mazzioni et al. (2017), cujas evidências apresentaram uma relação positiva entre evidenciação ambiental e rentabilidade.

Já a variável Tamanho apresentou uma correlação positiva, porém não significativa estatisticamente com a variável evidenciação ambiental, corroborando com os resultados encontrados por Fernandes (2013), o qual constatou uma associação positiva entre tamanho da empresa com evidenciação ambiental. No entanto, o endividamento possui correlação negativa com a variável evidenciação ambiental de forma negativa, porém não significativa ao nível de 10\%. Já a variável ISE apresenta uma correlação negativa com a evidenciação, tais resultados não corroboram 
com os achados de Murcia et al. (2008); Almeida et al. (2012); Marquezan et al. (2015) e Rover et al. (2012), que observaram que as empresas que participam do ISE apresentam maior disclosure verde, logo associação positiva entre eles.

Em relação à variável Auditoria, observouse uma correlação negativa e não significativa com a variável evidenciação ambiental, divergindo dos resultados identificados por Murcia et al. (2008) e Rover et al. (2012) que identificaram relação positiva entre esse item e evidenciação ambiental.

Adicionalmente, foi realizado um teste de legibilidade das informações divulgadas pelas empresas. O grau de legibilidade ou complexidade foi extraído por meio do programa "Gunning's Fog Index" representado pela fórmula 1.

$$
\mathrm{GFI}=\left[\left(\frac{\text { número de palavras }}{\text { número de frases }}\right)+(\text { número de palavras difíceis })\right] \cdot 0,4
$$

O objetivo desse programa de legibilidade é determinar o quão difícil é ler e entender determinada informação divulgada. "Palavras difíceis" representam as palavras complexas que são escritas no decorrer do texto. Quanto maior (menor) a classificação de acordo com o índice, mais (menos) complexa é a leitura do texto. Dessa forma, o FOG Index testa a legibilidade do texto e calcula a média ponderada do número de palavras por frase, bem como o número de palavras longas (três ou mais sílabas), gerando um índice com estas observações agrupadas (GUNNING, 1952). A interpretação adequada da escrita profissional deve apresentar um índice entre 10 e 15. Assim, um índice maior que 15 indica que o texto apresenta uma linguagem complexa e, um índice abaixo de 10 aponta para um texto muito simplificado (GUNNING, 1952).

Em pesquisas anteriores, autores, como Miller (2010), Courtis (1986), Courtis (1995), Lehavy, Li e Merkley (2011), Curto (2014), Fakhfakh (2015), Buschee, Gow e Taylor (2017), Reina et al. (2017), Silva et al. (2017a) e Silva et al. (2017b) já utilizaram ferramentas de medição de legibilidade para verificar o grau de complexidade das palavras. Alguns autores defendem que: os níveis de legibilidade dos relatórios financeiros impactam negativamente o princípio da comunicação eficaz quando apresentados de forma distorcida (COURTIS, 1986); resultados são gerenciados para deixar as informações divulgadas menos legíveis (LI, 2008); linguagem de comunicação mais complexa é adotada para confundir os usuários (RENNEKAMP, 2012); informações mais complexas são divulgadas e ofuscadas sob a bandeira da legalidade e tecnicalidade dos relatórios divulgados (LO; RAMOS; ROGO, 2017); e, relatórios com informações mais complexas prejudicam sua usabilidade (LEHAVY; LI; MERKLEY, 2011).

Conforme a Tabela 5, observa-se que quase todas as empresas apresentaram relatórios com baixa legibilidade, ou seja, aproximadamente $87 \%$ das empresas analisadas apresentaram grau de complexidade acima de 15 pontos, tanto nas demonstrações financeiras como no relatório ambiental, e, portanto, com compreensão difícil. Outras pesquisas com outros setores, talvez pudessem confirmar se esse percentual alto é próprio das características do setor; se ocorre também em outros setores ou ainda analisar outras variáveis para perceber se essas empresas estão dificultando a evidenciação para ocultar notícias desfavoráveis a elas. 
Tabela 5 - Teste de Legibilidade

\begin{tabular}{l|l|c|c}
\hline \multirow{2}{*}{ Empresas / Ano } & \multirow{2}{*}{ Tipo de Relatório } & \multicolumn{2}{l}{ Gunning's Fog Index } \\
\cline { 3 - 4 } & & 2015 & 2016 \\
\hline \multirow{2}{*}{ FIBRIA } & DFs & 25,47 & 18,21 \\
\cline { 2 - 4 } & Relatório Ambiental & 21,38 & 22,75 \\
\hline \multirow{2}{*}{ IRANI } & DFs & 20,59 & 20,57 \\
\cline { 2 - 4 } & Relatório Ambiental & - & 19,36 \\
\hline \multirow{2}{*}{ KLABIN } & DFs & 20,04 & 12,74 \\
\cline { 2 - 4 } & Relatório Ambiental & 24,94 & 25,33 \\
\hline \multirow{2}{*}{ SUZANO } & DFs & 18,65 & 28,35 \\
\cline { 2 - 4 } & Relatório Ambiental & 27,99 & 22,35 \\
\hline
\end{tabular}

Fonte: Dados da pesquisa.

A empresa Suzano, por exemplo, apresentou no ano de 2015 um relatório ambiental com grau de complexidade de leitura $46 \%$ acima do que é considerado informação complexa (15 graus). A mesma empresa também apresentou no ano de 2016 demonstrações financeiras 47\% acima do que é considerado como informação complexa. Aqui caberia uma pesquisa mais aprofundada para verificar se esses aumentos da complexidade dos relatórios se deram em função dos problemas ambientais de Mariana/MG, os quais ganharam evidências no ano de 2015, ou se antes mesmo desse desastre as empresas já apresentavam relatórios com baixa legibilidade.

De acordo com Curto (2014), a avaliação da qualidade de um texto é baseada na estrutura, escrita e na facilidade de sua leitura. Para Fakhfakh (2015), a compreensão está relacionada, linguisticamente, à percepção do significado correto do texto, assim como a inteligibilidade em que os leitores podem ler determinado conteúdo da informação e conseguir captar o significado das ideias apresentadas. No relatório corporativo, a narrativa textual representa a grande maioria da divulgação sendo, em média, $80 \%$ de um relatório anual, por exemplo, em relação ao restante, que consiste em números e representação de dados quantitativos (LO; RAMOS; ROGO, 2017). Segundo Courtis (1995), um dos princípios da comunicação efetiva é que as mensagens recebidas pelos leitores sejam interpretadas da mesma forma que o pretendido pelo remetente. Assim, percebe-se uma baixa legibilidade apresentada pelas empresas e que essa complexidade interposta entre empresas e seus usuários pode prejudicar os $80 \%$ de informação que as empresas pretendem comunicar aos seus usuários.

\section{CONSIDERAÇÕES FINAIS}

Esta pesquisa tem como objetivo investigar o nível de evidenciação ambiental, grau de legibilidade dos relatórios e a associação do nível de evidenciação com as variáveis tamanho, rentabilidade, endividamento, empresas auditadas por Big Four de auditoria em empresas do segmento de papel e celulose, listadas na bolsa de valores Brasil, Bolsa e Balcão (B3).

Os resultados obtidos indicam que as empresas do ramo de papel e celulose apresentam um 
maior nível de evidenciação ambiental em suas publicações quando comparado com todas as empresas listadas na B3 (ALMEIDA et al., 2012; ALTOÉ et al., 2013). Os percentuais encontrados para os tipos de evidenciação sugerem que o ramo de papel e celulose se destaca quando comparado a determinados ramos de atividade e ao total das empresas listadas na B3, publicando mais suas informações ambientais com cunho quantitativo não monetário e aumentando a divulgação das informações de forma quantitativa monetária, apesar da forma predominante ser do tipo declarativa (ALTOÉ et al., 2013; MURCIA et al. 2008).

Quanto à correlação entre as variáveis, constatouse que para o ramo de papel e celulose o tamanho da empresa, o endividamento, a empresa de auditoria e fazer parte do ISE apresentam correlação negativa com a variável evidenciação ambiental. A variável rentabilidade não apresentou correlação com a evidenciação ambiental. No entanto, nenhuma das correlações com a variável evidenciação ambiental foi estatisticamente significativa ao nível de 10\%.

Diante do exposto, pode-se concluir que apesar dos esforços das empresas em melhorar a qualidade de suas informações, ainda se percebe que entraves da comunicação efetiva diminui a legibilidade de seus relatórios e como consequência informações mais complexas são geradas e informadas aos seus usuários. Nesse sentido, se o objetivo das empresas é mostrar sua preocupação com os aspectos ambientais que envolvem suas atividades seria necessário avaliar quais informações ambientais seriam prioritárias e qual o grau de complexidade com o qual as empresas pretendem divulgar isso.

Por fim, sugere-se para pesquisas futuras, estudos que lancem mais luz sobre as categorias e subcategorias dos efluentes e dos impactos nos recursos hídricos. Essa perspectiva poderia ainda ser adaptada para cada ramo de atividade de maneira que fique mais adequada às atividades operacionais daquele ramo, mostrando assim maior veracidade nas relações dos itens com as variáveis estudadas e com o nível de disclosure verde e as possíveis explicações para a evidenciação ambiental das empresas. Recomenda-se ainda um estudo mais aprofundado com as empresas específicas desse setor, pois a empresa Santher, por exemplo, apenas no ano de 2016 foi notificada 155 vezes e multada em todos os meses do ano de 2016. Ou seja, mesmo sem floresta/celulose ela também precisaria evidenciar os itens descritos na categoria de Murcia et al. (2008) em função de pertencer ao mesmo segmento e uma pesquisa mais detalhista poderia, inclusive, identificar quais os fatores que estão mais impactando na divulgação dessas empresas, e acarretando tantas notificações e multas. 


\section{REFERÊNCIAS}

ALMEIDA, P. S. et al. Nível de disclosure verde e a reputação corporativa ambiental das companhias brasileiras de capital aberto.

Revista Contemporânea de Contabilidade, v. 9, n. $18,2012$.

ALTOÉ, S. M. L. et al. Perfil das informações ambientais: um estudo exploratório em empresas dos setores siderúrgico e metalúrgico.

Revista Ambiente Contábil, v. 5, n. 2, p. 209, 2013.

ANTONOVZ, T. Contabilidade Ambiental. 1. ed. Curitiba: Editora Intersaberes, 2014.

BM\&FBOVESPA. A Nova Bolsa. Disponível em: http://www.bmfbovespa.com.br. Acesso em: jun. 2016.

BRASIL, Lei. 6.938, de 31 de agosto de 1981. Dispõe sobre a Política Nacional do Meio Ambiente, seus mecanismos de formulação e aplicação, e dá outras providências. Publicado no DOU em, v. 2, 1981.

BRASIL, Lei. 10.165, de 27 de dezembro de 2000. Altera a Lei no 6.938, de 31 de agosto de 1981, que dispõe sobre a Política Nacional do Meio Ambiente, seus fins e mecanismos de formulação e aplicação, e dá outras providências, v. 2, 2000.
CONSELHO FEDERAL DE CONTABILIDADE (CFC). Norma Brasileira de Contabilidade Técnica $\mathbf{N}^{\circ}$ 15. Disponível em: http://www1.cfc.org.br/sisweb/ sre/detalhes_sre.aspx? Codigo $=2004 / 001003$. Acesso em: 12 maio 2016.

COURTIS, J.K. Readability of annual reports: Western versus Asian evidence. Accounting, Auditing and Accountability Journal, v.8, n.2, p.4-17, 1995.

CURTO, P. S. L. Classificador de Textos para o Ensino de Português como Segunda Língua. 2014. 132 f. Dissertação (Mestrado em Engenharia) - Universidade de Lisboa, Lisboa, Portugal, 2014.

CVM (Comissão de Valores Mobiliários). Parecer de Orientação CVM n 15, de 28 de dezembro de 1987. Disponível em: http://www.cvm.gov.br/ legislacao/pare/pare015.html. Acesso em: 04 jun. 2016.

DA COSTA, R. S.; MARION, J. C. A uniformidade na evidenciação das informações ambientais. Revista Contabilidade \& Finanças, v. 18, n. 43, p. 20-33, 2007.

DOS REIS, L. G.; NOGUEIRA, D. R.; TARIFA, M. R. Uma análise histórica das publicações existentes sobre o tema contabilidade ambiental. Revista de Estudos Contábeis, v. 2, n. 3, p. 90-97, 2012. 


\section{REFERÊNCIAS}

FAKHFAKH, M. The readability of international illustration of auditor's report: $\mathrm{Na}$ advanced reflection on the compromise between normative principles and linguistic requirements. Journal of Economics, Finance and Administrative Science, v. 20, n. 38, p. 21-29, 2015.

FERNANDES, S. M. Fatores que influenciam o disclosure ambiental: Um estudo nas empresas brasileiras no período de 2006 a 2010. Revista Ambiente Contábil, v. 5, n. 2, p. 250, 2013.

FIORI, F A. O Reconhecimento de passivos ambientais em empresas do setor mineral. 2011. Tese de Doutorado. Universidade Federal do Rio Grande do Sul.

GIL, A. C. Métodos e técnicas de pesquisa social. 6. ed. São Paulo: Atlas, 2008.

GUNNING, R. The Technique of Clear Writing. McGraw-Hill. pp. 36-37. 1952.

IUDÍCIBUS, Sérgio de. Teoria da contabilidade. 7. ed. São Paulo: Atlas, 2004.

LAKATOS, E. M.; MARCONI, M. A. Fundamentos de metodologia científica. 5. ed. São Paulo: Atlas, 2003.

LEHAVY, R.; LI, F.; MERKLEY, K. The effect of annual report readability on analyst following and the properties of their earnings forecasts. The Accounting Review, v.86, n.3, p.10871115, 2011.
LI, F. Annual Report Readability, Current Earnings, and Persistence. Journal of Accounting and Economics, v.45, p.221-247, 2008.

LO, K.; RAMOS, F., ROGO, F. Earnings management and annual report readability. Journal of Accounting and Economics, v.63, n.1, p.1-25, 2017.

LUDKE, M.; ANDRÉ, M. E. D. A. Pesquisa em educação: abordagens qualitativas. São Paulo: EPU, 1986.

MARQUEZAN, L. H. F. et al. Análise dos determinantes do disclosure verde em relatórios anuais de empresas listadas na BM\&FBovespa. Contabilidade, Gestão e Governança, v. 18, n. 1, 2015.

MAZZIONI, S. et al. Influência da Governança Corporativa na Evidenciação Voluntária de Informações de Natureza Socioambiental. Revista Organizações em Contexto, v. 13, n. 26, p. 311338.

MURCIA, F. Da-Ri et al. 'Disclosure Verde' nas Demonstrações Contábeis: Características da Informação Ambiental e Possíveis Explicações para a Divulgação Voluntária. Contabilidade, Gestão e Governança, v. 11, n. 1-2, 2009.

MUSSOI, A.; VAN BELLEN, H. M. Evidenciação ambiental:uma comparação donível deevidenciação entre os relatórios de empresas brasileiras. Revista de Contabilidade e Organizações, v. 4, n. 9, p. 55-78, 2010. 


\section{REFERÊNCIAS}

NOSSA, V. Disclosure ambiental: uma análise do conteúdo dos relatórios ambientais de empresas do setor de papel e celulose em nível internacional. 2002. Tese de Doutorado. Universidade de São Paulo.

Norma e Procedimento de Auditoria n.11 do Instituto dos Auditores Independentes do Brasil - IBRACON. Disponível em http://www.ibracon. com.br/ibracon/Portugues/detPublicacao. php?cod=124. Acesso em: 04 jun. 2016.

PEREIRA, M. T.; LERNER, A. F.; VENDRUSCOLO, M. I. Acidente Ambiental em Mariana-MG: Um Estudo dos Impactos Econômicos e Financeiros nas Empresas Responsabilizadas. In: XVIII USP International Conference in Accounting. 2018. p. 1-20.

RENNEKAMP, K. Processing Fluency and Investors' Reactions to Disclosure Readability. Journal of Accounting Research, v. 50, p. 1319-1354, 2012.

RIBEIRO, M. S. Contabilidade ambiental. 2. Ed. São Paulo: Saraiva, 2006.

RODRIGUES, J. M.; MACHADO, D. G.; CRUZ, A. P. C. Evidenciação de custos ambientais em empresas do segmento de adubos e fertilizantes, Revista Contemporânea de Contabilidade, v. 8, n.15, p. 63-86, 2011.

ROVER, S. et al. Explicações para a divulgação voluntária ambiental no Brasil utilizando a análise de regressão em painel. Revista de Administração, v. 47, n. 2, p. 217-230, 2012.
SALOMONE, R.; GALLUCCIO, G. Environmental issues and financial reporting trends: a survey in the chemical and oil \& gas industries. Working paper: University of Messina. 2001.

SANTOS, A. O. et al. Contabilidade ambiental: um estudo sobre sua aplicabilidade em empresas brasileiras, Revista Contabilidade \& Finanças, v. 12, n. 27, p. 89-99, 2001.

SANTOS, G. N. M.; VASCONCELOS, M. J. A.; LIMA, A. C. S. Desastre ambiental em Mariana, Minas Gerais (MG): um estudo à luz da teoria da Legitimidade. Revista Brasileira de Contabilidade, n. 229, p. 14-29, 2018.

SILVA, T. L. et al. Environmental disclosureinformações sobre resíduos sólidos divulgadas pelas empresas potencialmente poluidoras listadas na BM\&FBovespa. Revista Ambiente Contábil, v. 5, n. 2, p. 229-249, 2013.

SILVA, W. et al. Custo da Complexidade Informacional e Legibilidade dos Relatórios de Auditoria. In: Anais do Congresso Brasileiro de Custos-ABC. 2017.

TEIXEIRA, A. J. C.; NOSSA, V.; DONATTI, V. P. O tratamento contábil para os gastos com reflorestamento de áreas degradadas ambientalmente: um estudo exploratório. CONGRESSO USP DE CONTROLADORIA E CONTABILIDADE. 2007. Anais [...]. 2007. 


\section{REFERÊNCIAS}

TINOCO, J. E. P.; KRAEMER, M. E. P. Contabilidade e gestão ambiental. 3. ed. São Paulo: Atlas, 2011.

TINOCO, J. E. P.; ROBLES, L. T. A contabilidade da gestão ambiental e sua dimensão para a transparência empresarial: estudo de caso de quatro empresas brasileiras com atuação global. Revista de Administração Pública RAP, v. 40, n. 6, p. 1077-1096, 2006.

TOLEDO JUNIOR, M. S.; RIBEIRO, M. S. Os efeitos econômicos do rompimento de barragem de resíduos: divulgações nas demonstrações contábeis comparativamente à grande mídia. Revista de Administração da UFSM, vol. 10, p. 100-116, 2017.

\section{Lais Leoni Forechi ${ }^{1}$}

Graduada em Ciências Contábeis pela Universidade Federal do Espírito Santo - UFES/ ES, Vitória/ES, Brasil. E-mail: laisforechi@gmail. com

\section{Diane Rossi Maximiano Reina ${ }^{2}$}

Doutora em Controladoria e Contabilidade pela Universidade de São Paulo - FEA/USP/ SP - Brasil. Professora do Programa de PósGraduação em Ciências Contábeis (PPGCON) e do Departamento de Ciências Contábeis da Universidade Federal do Espírito Santo - UFES/ES, Brasil. E-mail: dianereina@hotmail.com

\section{Donizete Reina ${ }^{3}$}

Doutorando em Ciências Contábeis na Universidade Federal de Uberlândia - UFU/MG - Brasil. Professor do Departamento de Ciências Contábeis da Universidade Federal do Espírito Santo - UFES/ES. Campus Goiabeiras - Vitória/ES Brasil. E-mail: dreina2@hotmail.com

\section{Laís Franca Narciso ${ }^{4}$}

Mestra em Controladoria e Finanças pela Universidade Federal do Espírito Santo, Professora do Departamento de Ciências Contábeis da Universidade Federal do Espírito Santo - UFES

Campus Goiabeiras - CEP: 29075-010 - Vitória/ ES - Brasil E-mail: lais.fnarciso@gmail.com

Recebido em: 25/07/2018 Aprovado em:15/01/2019 